Braz J. ver. Res. anim. Sci.,

Sãn Paulo, v.31. n.3/4, p.261-6, 1994

\title{
CERATITE ULCERATIVA EM ROEDOR SILVESTRE (Agouti paca)
}

\author{
ULCERATIVE KERATITIS IN WILD RODENT (Agouti paca)
}

José Luis I.AUS'; Tatiana Monreal Ramos NOGUEIRA²; Newton NUNES'; Mirian Siliane Batista de SOUZA`; Adriana MORALES"

\section{RESUMO}

\begin{abstract}
Os autores relatam caso de oftalmopatia de diagnóstico e descrição raros por tratar-se de animal silvestre (Agouti paca). Referem-se à ocortência de ceratite do tipo ulcerativa, com apresentação e sinais clăssicos, em um exemplar adulto, fêmea, proveniente do Criadouro de Animais Silvestres da Faculdade de Ciências Agrárias e Veterinàrias de Jaboticabal-UNESP, examinado junto ao Serviço de Oftalmologia do Hospital Veterinário da referida entidade.
\end{abstract}

UNITERMOS: Cómea; Úlcera; Animais silvestres

\section{INTRODUÇÃO}

As pacas são mamíferos pertencentes à Ordem dos Roedores que vivem na América Tropical (COLLET ${ }^{4}, 1981$; WALKER ${ }^{33}$, 1983). São encontradas em matas ralas, florestas e bosques, em troncos ocos, debaixo de pedras ou em tocas, sempre na proximidade de rios ou lagoas (SANTOS ${ }^{27}$, 1984; DEUTSCH; RODRIGUES ${ }^{6}, 1989$; MATAMOROS ${ }^{19}$, 1985; EMMONS $^{8}$. 1990). Alimentam-se de frutas, sementes, raízes, grãos, folhagens e culturas.

Noturnas, terrestres e solitárias, raramente em pares, permanecem entocadas durante o dia para saírem à noite em busca de alimento. Quando ameaçadas, refugiam-se em lagoas e rios. São boas nadadoras e copulam na água (DEUTSCH; PUGLIA ${ }^{5}$, 1988; DEUTSCH; RODRIGUES ${ }^{6}$, 1989; SMYTHE 29,1991 ).

Os animais adultos medem entre 50 e $60 \mathrm{~cm}$ de comprimento, com peso corpóreo variando entre 5 a $10 \mathrm{~kg}$. As fêmeas são menores que os machos. Possuem pelos curtos e eriçados, em tonalidades que vão do castanho pardo ao avermelhado. Faces lateral e inferior do focinho são brancas, como também o ventre. Há quatro faixas longitudinais salpicadas no flanco, de cor branco amarelada. Cauda vestigial é quase nula e as orelhas são pequenas.

Apresentadas as características inerentes ao animal, explicitarse-ão correlações entre as oftalmopatias mais comumente encontradas nas domésticas e aquelas que poderiam ser aventadas nas silvestres.
Assim, há que se considerar dentre as estruturas que constituem o aparelho da visāo, a córnea como alvo de inúmeras afecções. Porção da túnica fibrosa que reveste anteriormente o globo ocular, tem em suas patologias a causa mais comum de cegueira. Relacionam-se, entre as mais freqüentes, as ceratites ulcerativas, caracterizadas por perdas teciduais de epitélio e porções variadas de estroma (STARTUP ${ }^{30}, 1972$; VAUGHAN; ASBURY ${ }^{32}$, 1977), decorrentes de traumas, anormalidades palpebrais, ciliares e do aparelho lacrimal (VAUGHAN; ASBURY Y2, 1977; NELSON; MacMILLAN ${ }^{21}$, 1988; KERN ${ }^{13}$, 1990; SLATTER ${ }^{28}$, 1990). Interpõem-se as infecções bacterianas, micóticas e virais, as deficiências nutricionais, e as neurotróficas (STARTUP ${ }^{31}$, 1984; HELPER $^{10}$, 1989; PORTNOY et al. ${ }^{25}$, 1989), bem como o estresse e os desequilíbrios orgânicos diversos (NASISSE ${ }^{20}$, 1985).

Habitualmente, têm sido classificadas em superficiais, profundas, serpiginosas ou dendríticas, nutricionais e neuroparalíticas. Quando superficiais, tendem a reorganizarse por mitoses e deslizamentos celulares centripetos (PERUCCIO $^{23}, 1983$; NASISSE ${ }^{20}, 1985$; LAFORGE $^{15}, 1989$; SLATTER $^{28}$, 1990). Quando profundas, indolentes e associadas a graus variados de contaminação, podem tornar-se graves e de destino inexorável (NASISSE ${ }^{20}, 1985$; SLATTER $\left.{ }^{28}, 1990\right)$.

Clinicamente, são abordadas por condutas dirigidas ao alívio dos sinais clínicos e ao impedimento do processo lítico. No

1 -Professor Assistente Doutor-Faculdade de Ciencias Agrárias e Veterinárias da UNFSP-Campus de Jaboticabal

2-Médica Veterinária. Bolsista-Faculdade de Ciéncias Agrárias e Veterinárias da UNESP.Campus de Jaboticabal

3-Professor Assistente-Faculdade de Ciencias Agrárias e Veterinárias da UNESP-Campus de Jaboticabal

4-Académica de Pós-Graduaçào em Cinurgia Veterinária-Faculdade de Ciências Agrárias e Veterinárias da UNESP-Campus de Jaboticabal

5-Acadêmica de Pós-Graduação em Patologia Animal-Faculdade de Ciẻncias Agrárias e Veterinárias dà UNFSP-Campus de Jaboticabal 
que concernc a tal, os procedimentos indicam terapia antimicrobiana, cicloplégica, de lubrificação ocular, cauterização química, dietas apropriadas c, ainda, soluçōes ou pomadas hiperosmóticas. Há que se explicitar a terapêu(ica anticolagenolítica, alvo, ainda, de controvérsias (STARTUP') 1984: NASISSF 20. 1985: HEI.PER ${ }^{10}, 1989$; KF:RN ${ }^{13}, 1990 ;$ SLATTH:R $\left.{ }^{28}, 1990\right)$.

Cirurgicamente, reportam-se fatos interessantes. Amontamse por exemplo. os primeiros relatos sobre ceratoplastias, por QUENCiSY2"(1789), em que o autor propõe a substituição de porção da fúnica lesada por discos de vidro fixados com fïo de sedal.

Técnicas de transplantação homóloga tiveram. entre os pioneiros, L.ARSSON ${ }^{16} \mathrm{em} 1948$ que empregou enxerto escleral no recobrimento de perfuraçōes comeanas. Procedimentos em auto e homotransplantação foram sobejamente empregados (BERNIS 2 . 1961: JFNSEN 12. 1963: DICE I1 el al. ${ }^{7}, 1973$; MacL.AUGHLIN et al. ${ }^{18}$, 1984; HACKER?. 1988; BRIGHTMAN el al. ${ }^{3}, 1989$ ).

A utilização de tecidos colhidos à distância do foco primário, tormou-se alternativa adjutória. KOENIG; KAUFMAN ${ }^{14}$ (1983) e PORTNOY el al. ${ }^{25}$ (1989) idealizaram empregar enxertos de periósteo. BARROS el al.' (1990) estudaram ceratoplastias por enxertos de pericárdio com bons resultados.

Proposituras envolvendo suturas diretas (PEIFFER JUNIOR et al. 22, 1987: HEL.Pl: ${ }^{10}, 1989 ;$ KFRN $^{13}, 1990$; WHITI.FY $Y^{3-4}$, 1991), adesivos (PORTNOY et al. ${ }^{25}, 1989$; LAUS et al. ${ }^{17}$, 1992), lentes de contato flexiveis (HERMANN"1, 1989; POR'TNOY et al. ${ }^{25}$. 1989) e película celulósica (PIPPI; SAMPAIO ${ }^{2 \downarrow} \cdot 1900$ ), foram lambém investigadas.

İm mattéria cujas particularidades muitas vềes se sobrepôem a análise genérica, encontrou-se motivação para levar a termo a apresentação de um caso. cuja importância não se tradu\% pela natureza em si do fenômeno, mas, fundamentalmente, pelo paciente alvo em que se manifestou. Neste contexto, inserem-se os objetivos da propositura, singela em sua apresentação, porém complexa em suas implicações.

\section{MATERIAL, E MÉTODO}

\section{MATERIAL. BIOLÓGICO}

Animal silvestre (Agouti paca) popularmente conhecido por paca, da Ordem dos Roedores, adulto, fêmea, pertencente ao Criadouro de Animais Silvestres da Faculdade de Ciências

\footnotetext{
- Valium Lib. Riche
}

** Ketalar - Liah. Parke-1)avis
Agrárias e Veterinárias de Jaboticabal-UNE:SP, atendido junto an Serviço de Oftalmologia do Hospital Veterinário "Governador Laudo Natel" da referida entidade.

\section{HISTÓRIA CLÍNICA}

Animal mantido em cativeiro. alimentado com frutas da época, culturas de milho. mandioca è ração apropriada oferecida "ad libitum". manifestando desconforto ocular unilateral, com evolução de aproximadamente 30 dias. Igualmente, sinais de oligorexia e discreta apatia.

\section{SLMIOTÉCNICA}

Após prévia anestesia pela associação de diazepan* (l mg/ $\mathrm{kg} / \mathrm{IM}$ ) com cloridrato de quetamina** (.5mg/kg/lM), levouse em consideração, na ordem, avaliação das condições gerais, palpebrais, do aparelho lacrimal, de conjuntivas palpebral e bulbar, túnica externa e úvea anterior. Ressaltaram-se: fotofobia, blefarospasmo e epifora. Amontaram-se, congestão em vasos conjuntivais, neovasos prolundos e opacificação sediados ao centro da túnica (Fig. 1). con prova de fluoresceína*** positiva (Fig. 2).

\section{TERAPÊUTICA}

Basearam-se as medidas de forma a contemplar praticidade e baixos custos. Por tratar-se de lesāo superficial, dirigiramse os protocolos à profilaxia da infecção e, adjutoriamente. à estimulação da cicatrização. empregando-se pomada oftálmica à base de clorantenicol e vitamina $A^{* * * *} 5 \mathrm{x} / \mathrm{dia} / 15$ dias. Também por razões de custo, dispensaram-se os inibidores de colagenase, bem como técnicas de ceraloplastia, cuja adoção esteve condicionada à evolução do processo e à presença de sinaris de indolência.

\section{RESULTADOS}

Verificaram-se frente ao acompanhamento temporal do paciente, desenvolvimentos clínico e oftálmico satisfatórios. com evolução para a cura.

Sinais de recrudescência não foram vistos no decurso dos dias que se seguiram. Pequena cicatriz estromal, de pouco signilicado clínico, apresentou-se como seqüela.

\section{I)ISCUSSÃO}

Imputadas como as mais freqüentes causadoras de morhidade ocular e cegueira, as afecções em córnea tem sido alvo de inúmeras investigações. Há que se destacar aquelas vincula- 


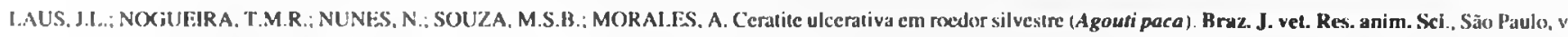
31. ก..3/4, p. $261-6,1994$.

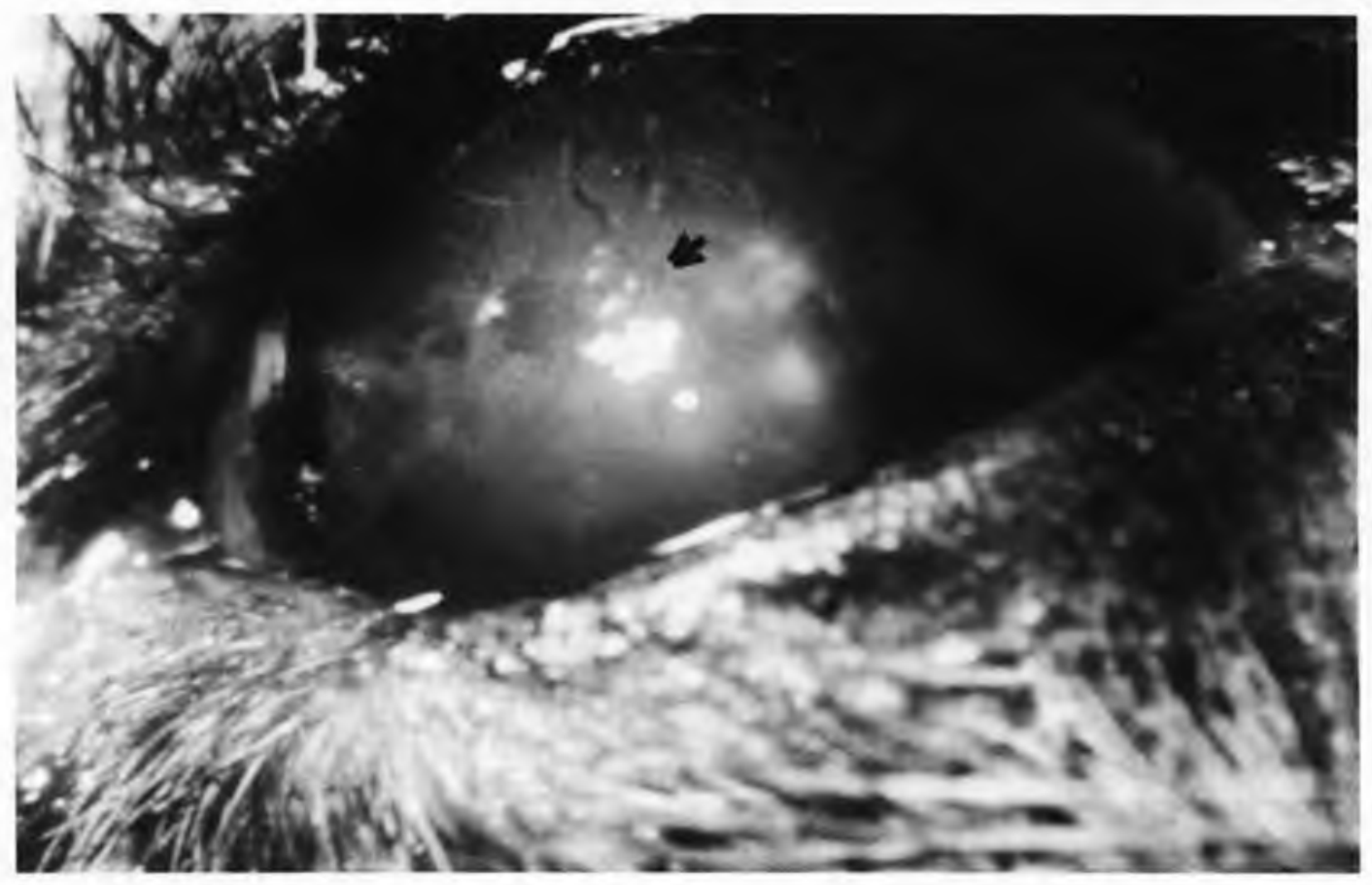

\section{FIGURA 1}

Imagem fotográfica de córnea de paca (Agouti paca) exibindo neovasos profundos e opacificação.

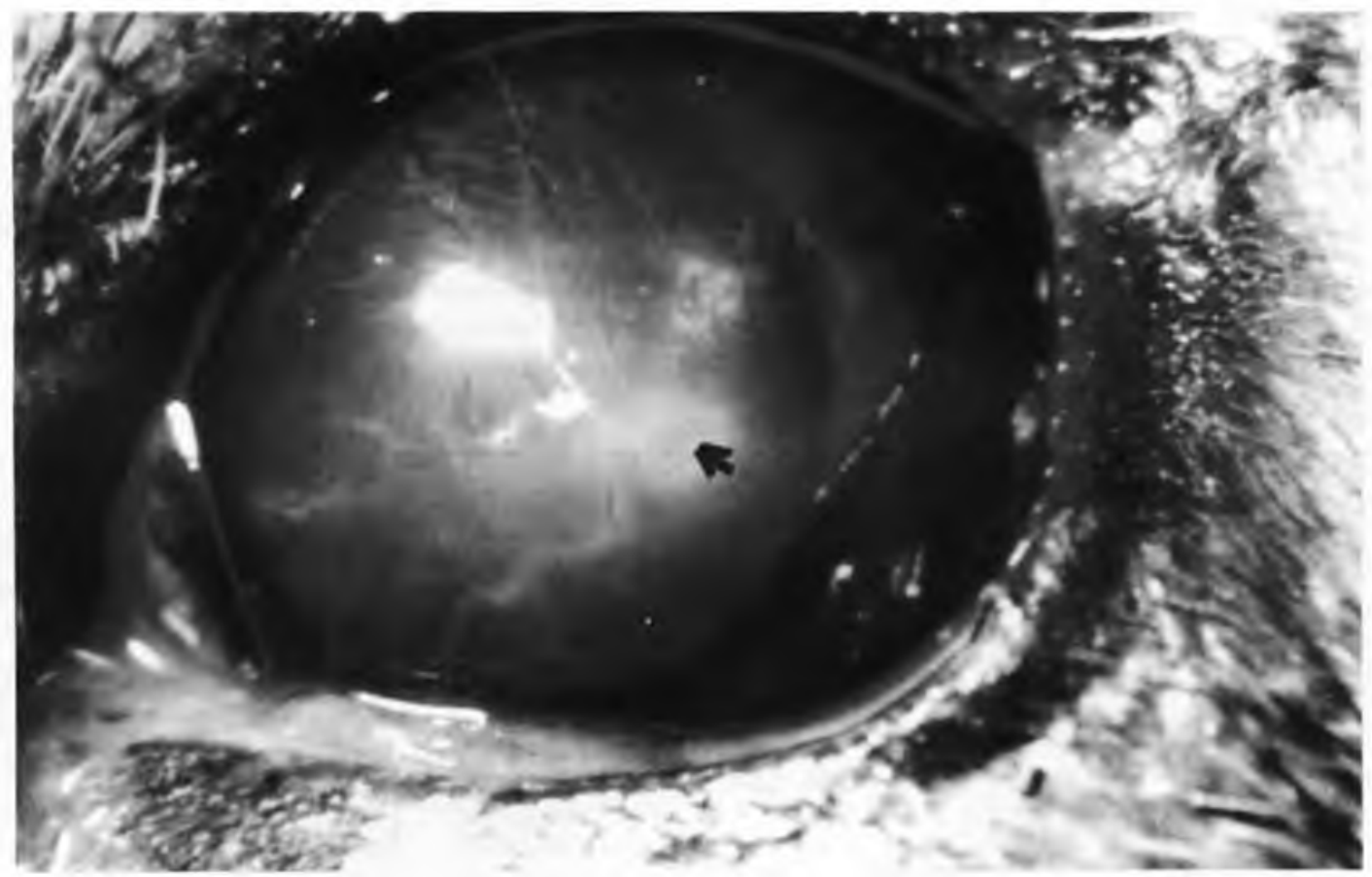

FIGURA 2

Imagem fotográfica de córnea de paca (Agouti paca) exibindo úlcera com neovasos profundos e opacificação. Notar impregnação pela fluoresceína. 


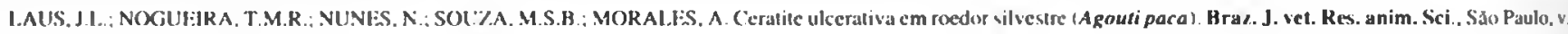
31, n. 3/4. p. $261-6.1994$

das às perdas teciduais de epitélio e porçōes variáveis de estroma (STARTUP30, 1972; VAUGHAN; ASBURY32, 1977). os traumas, as anormalidades palpebrais, as ciliares $\mathrm{e}$ as do aparelho lacrimal (VAUGHAN; ASBURY ${ }^{32}, 1977$; NELSON; MacMILLAN ${ }^{21}$, 1988; KERN ${ }^{13}, 1990$; SLAT'TER $\left.{ }^{28}, 1990\right)$.

Amontam-se as infecçōes bacterianas, micóticas e virais, entre outras que não raro atuam (STARTUP ${ }^{31}, 1984$; HELPI:R ${ }^{10}$, 1989; PORTNOY et al. ${ }^{25}$, 1989).

Não se pode determinar a condição gênica envolvida com o caso, embora hipoteticamente permitiu-se admitir origem traumática.

Ainda que a apresentação, em sua forma clínica, corroborasse firmar diagnóstico de úlcera do tipo superficial, havia indolência c. porquanto, cronicidade. PERUCCIO ${ }^{23}$ (1983), NASISSE:20)(1985), LAFORGE $^{15}$ (1989), SLATTER ${ }^{28}$ (1990) observaram reparação espontânea de úlceras superficiais via deslizamentos e mitoses celulares. NASISSF ${ }^{20}$ (1985) e SLATTI:R 28 (1990) constataram indolência em lesôes contaminadas por agentes bacterianos, obrigando intervenção rápida. Discernir entre condutas clínicas, comparativamente a manobras cirúrgicas, representa propiciar limites entre exito e insucesso.

STARTUP"1 (1984), NASISSF 20 (1985), HELPER 10 (1989), KERN $^{13}$ (1990), SLATTER ${ }^{28}$ (1990) fundamentaram as manobras médicas no alívio dos sinais clínicos e na profilaxia de descemetoceles. Preconizaram terapia antomicrobiana, cicloplégica, de lubrificação ocular, cauterização química. dietas apropriadas e soluções hiperosmóticas. No que conceme a tal, por razões de custo e praticidade, procurou-se nortear as condutas para procedimentos exclusivamente clínicos. Delineou-se institutir terapia antimicrobiana, dispensando-se medidas adjutórias. Preteriram-se técnicas de ceratoplastia. Tais práticas foram exaustivamente descritas (QUENGSY ${ }^{26}$, 1789; LARSSON ${ }^{16}, 1948$; BERNIS $^{2}, 1961$; JENSEN ${ }^{12}, 1963$; DICE II et al. ${ }^{7}$ 1973; MacLAUGHLIN et al. ${ }^{18}$, 1984; HACKER ${ }^{4}, 1988$; BRIGHTMAN ct al. ${ }^{3}, 1989$ ). Juntam-se a estas, os trabalhos de KOENIG; KAUFMAN ${ }^{14}$ (1983) e PORTNOY et al.25 (1989).

BARROS et al.' (1990) apresentaram procedimento singular com base na utilização de pericárdio de equuino conservado em glicerina. PEIFFER JUNIOR et al. ${ }^{22}$ (1987), HELPER ${ }^{10}$ (1989), KERN ${ }^{13}$ (1990), WHITLEY ${ }^{34}$ (1991) preconizaram suturas diretas. PORTNOY et al. ${ }^{25}$ (1989). LAUS et al. ${ }^{17}$ (1992) estudaram adesivos para ambientes cirúrgicos. HERMANN ${ }^{11}$ (1989) c PORTNOY et al. ${ }^{25}$ (1989) investigaram lentes de contato, e PIPPI: SAMPAIO-4 (1990) empregaram película celulósica.

Cotejar tais procedimentos, com os aqui adotados, é prática inexequível, pois os mesmos não foram instituídos no decurso da terapêutica delineada. Não obstante, trata-se de altemativas de grande valor técnico.

\section{SUMMARY}

The authors described a case of ocular disease of rare diagnosis and description, in an agouti (Agouti paca). It is a casuistic case of ulcerative keratitis with manifestation of classical signals. in one adult female coming from the Animal Section of the Faculdade de Ciencias Agrarias e Veterinarias de Jaboticabal-UNESP, that had been examined at the Ophthalmology Service of the Veterinary Hospital of the same school.

UNITERMS: Cornea; ulcers; wild animals; agouti

\section{REFERÊNCIAS BIBLIOGRÁFICAS}

01-BARROS.P.S.M.;SAFATLE, A.M.V.; MALERBA, T.A.; BURNIER JUNIOR, M. Reparação cirúrgica da córnea de cães usando pericárdio de equiunos conservado em glicerina. In: CONGRESSO BRASILEIRO DA ANCLIVEPA. 13., Gramado, 1990. Resumos. Gramado, ANCLIVEPA, 1990. p.11.

02-BH:RNIS, W.O. Further trials with parcial penetrating keratoplasty in dogs. Southwest Vet., v. 15, p.30-44, 1961.
03-BRIGHTMAN, A.H.; MacLAUGHLIN, S.A.; BRODGON, J.D. Autogenous lamellarcorneal grafting in dogs.Journal of the American Veterinay Medical Association, v.195, p.469-75, 1989.

04-COLLET, S.F. Population characteristics of Agouti paca (Rodentia) in Colombia. In: PUBLICATIONS OF THE MUSEUM OF MICHIGAN STATE UNIVERSITY (BIOLOGICAL SERIES). Michigan. 1981. v.5, n.7, 601 p.

05-DEUTSCH. L.A.; PUGLIA. L.R.R. Os animais silvestres: proteção doença e manejo. Rio de janciro, Globo, 1988. 
LAUS. J.L.: NOGUEIRA, T.M.R.: NUNES. N.: SOUZA. M.S.B.; MORALFS, A. Ceratite ulcerativa em roedor silvestre (Agoufi paca). Braz. J. vet. Res. anim. Sci.. Silo Paulı, v. 31, n.3/4. p. 26I-6, 1994.

06-DEUTSCH, L.A.; RODRIGUES, S. A ficha do bicho: paca. Globo Rural, São Paulo, p.58-61, 1989.

07-DICE II, P.F.; SEVERIN, G.A.; LUMB, W.V. Experimental autogenous and homologous corneal transplantation in the dog. Journal of the American Animal Hospital Association, v.9, p.245-69, 1973.

08-EMMONS, L.H. Paca - Agouti paca. In: EMMONS, L.H. Neotropical rainforest mammals - A field guide. Chicago, The University of Chicago Press, 1990.

09-HACKER, D.V. Uses of frozen comeal grafts in veterinary ophalmology. Annual Science Program American Collegy Veterinary Ophthalmology.v.15, p.34, 1988.

10-HELPER, L.C. Diseases and surgery of the cornea and sclera. In: HELPER, L.C. Magrane's canine ophthalmology. 4. ed. Philadelphia, Lea \& Febiger, 1989. p.102-49.

11-HERMANN, K. Terapeutic use of hydrophilic contact lenses. In: KIRK, R.W.; BONAGURA, J.D. Current veterinary therapy: small animal practice. Philadelphia, W.B. Saunders, 1989. p.640-1.

12-JENSEN, E.C. Experimental corneal transplantation in the dog. Journal American Veterinary Medical Association, v.142, p.11-22, 1963.

13-KERN, T.J. Ulcerative keratitis. Veterinary Clinics of North American Small Animal Practice, v.20, n.3, p.643-65, 1990.

14-KOENIG, S.B.; KAUFMAN, H.E. The treatment of necrotizing scleritis with an autogenous periosteal graft. Ophthalmic Surgery, v.14, p.1029-32, 1983.

15-LAFORGE, H. Pathologie de la corneé chez les carnivores domestiques. Recueil Médecine Vétérinaire, v.165, n.3, p.247-56, 1989.

16-LARSSON, S. Treatment of perforated corneal ulcer by autoplastic scleral transplantation. British Journal Ophthalmology. v.32, p.54-7, 1948.

17-LAUS, J.L.; SOUZA, M.S.B.M.; ROSSI, M.A.; MORAES BARROS, P.S.; MORALES, A. Observações sobre emprego do Colagel na ceratoplastia experimental no cão (Canis familiaris). In: CONGRESSO BRASILEIRO DA ANCLIVEPA, 14., Salvador. Resumos. Salvador, Anclivepa, 1992.

18-MacLAUGHLIN, S.A. et al. Autogenous parcial thickness corneal grafting in the dog. Annual Science Program American College Veterinary Ophthalmology, v.147, p.156, 1984.

9-MATAMOROS, Y. Fauna: el tepezcuinte. Biocenosis, v.1, n.5, p.21-2, 1985.
20-NASISSE, M.P. Canine ulcerative keratitis.Compendium on Continuing Education. v.7, n.9, p.686-701, 1985.

21-NELSON, D.L.; MacMILLAN, A.D. Doenças da córnea. In: KIRK, R.W. Atualização terapêutica veterinária. São Paulo, Manole, 1988. v.1, p.808-17.

22-PEIFFER JUNIOR, R.L.; NASISSE, M.P.; COOK, C.S.; HARLING, D.E. Surgery of the canine and feline prbit, adnexa and globe. Part 6: Surgery of the cornea. Companion Animal Practice, v.1, n.7, p.3-13, 1987.

23-PERUCCIO, C. Diagnosi e trattamento delle lesioni corneali. Scienza Veterinaria, p.3-8, gennaio, 1983.

24-PIPPI, N.L.; SAMPAIO, A.J.S.H. Estudos preliminares sobre o comportamento do Biofill na ceratoplastia lamelar em coelhos. In: CONGRESSO BRASILEIRO DA ANCLIVEPA, 13., Gramado, 1990. Resumos p.5.

25-PORTNOY, S.L.; INSLER, M.S.; KAUFMAN, H.E. Surgical management of corneal ulceration and perforation. Surv. Ophthalmol., v.34, n.1, p.47-58. 1989.

26-QUENGSY, 1789 apud GUIMARÄES, R.Q. Ceratoplastia interlamelar xenogena de galinha em coelho; utilizando córneas conservadas em cloreto de sódio por três dias, um mês e 14 anos. Estudo biomicroscópico e histopatológico. Belo Horizonte, Faculdade de Medicina da Universidade Federal de Minas Gerais, 1979. Tese (Doutoramento em Oftalmologia).

27-SANTOS, E. Entre o gambá e o macaco. Vida e costumes dos mamíferos do Brasil. Belo Horizonte, Itatiaia, 1984. p.129-33.

28-SLATTER, D. Cornea and sclera. In: SLATTER, D. Fundamental of veterinary ophthalmology. 2.ed. Philadelphia, W.-B. Saunders, 1990. p.257-303.

29-SMYTHE, N. Microlivestock: Little-Known small animal with a promising economic future. Washington, National Academy Press, 1991. p.263-9: Paca.

30-STARTUP, F.G. The treatment of corneal ulcers. Journal of Small Animal Practice. v.13, p.601-6, 1972.

31-STARTUP, F.G. Comeal ulceration in the dog. Journal of Small Animal Practice, v.25, p.737-52, 1984.

32-VAUGHAN, D.; ASBURY, T. Córnea e esclerótica. In: VAUGHAN, D.; ASBURY, T. Oftalmologia geral. São Paulo, Ed. Universidade de São Paulo, 1977. p.71 87.

33-WALKER, E. Rodentia; Family Dasyproctidae. In: WALKER, E. Walker's mammals of the world. Baltimore, Johns Hopkins University Press, 1983. v.2, 


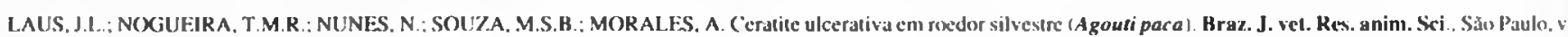
31, n.3/4. p. $261-6,1944$.

\section{p.814-8.}

34-WHITLEY, R.D. Canine cornea. In: GELATT, K.N. Veterinary ophthalmology. 2.ed. Philadelphia, Lea \& Febiger, 1991. p.307-56.
Recebido para publicacão em 08/06/93 Aprovado para publicacão em 23/1 1/93 